\section{A Survey of Tomato and Potato Fields in Florida Reveals Unique Genotypes of Phytophthora infestans between 2005 and 2007}

\author{
Diana Schultz \\ 769 Wilson Avenue, Fort Myers, FL 33919
}

\author{
Ryan S. Donahoo \\ University of Florida, Plant Pathology, Southwest Florida Research and \\ Education Center, 2685 SR 29 N, Immokalee, FL 34142
}

Frances G.M. Perez

USDA-ARS/PSI-GIFVL, BARC-West Beltsville, MD 20705

Sucel Tejeda

2209 NW 26th Pl, Cape Coral, FL 33993

\author{
Pamela D. Roberts ${ }^{1}$ \\ Education Center, 2685 SR 29 N, Immokalee, FL 34142 \\ Kenneth L. Deahl \\ USDA-ARS/PSI-GIFVL, BARC-West Beltsville, MD 20705
}

University of Florida, Plant Pathology, Southwest Florida Research and

Additional index words. late blight, tomato, Florida, US-20, US-21

\begin{abstract}
Late blight, caused by Phytophthora infestans, affects tomatoes and potatoes in Florida during the winter-spring crop season. During the 2005 season, severe late blight epidemics were observed in Florida prompting our survey. Isolates from 2005 to 2007 were characterized phenotypically based on growth on three media, mating type, pathogenicity, and sensitivity to metalaxyl and genotypically based on two isozymes, mitochondrial DNA (mtDNA), and genomic profiling using the RG57 probe. Isolates collected in this survey were all A2, mtDNA Ia, and either 100/100 (2005), or 100/122 (2006/2007) at the Gpi locus, and homozygous 100 at the Pep locus. Novel genotypes infecting tomato in Florida were observed based on the Gpi locus and RG57 genomic profile. We propose US-20 for the collection of clonal isolates recovered during the 2005 season and US-21 for clones recovered during 2006 and 2007 . In addition to these novel genotypes recovered from tomato, one isolate was recovered from potato representing the US-8 clonal lineage. The findings of the survey in south Florida and their implications are presented.
\end{abstract} by the stramenopile Phytophthora infestans is regarded as the world's most destructive crop disease and has been considered a threat to global food security (Birch and Whisson, 2001; Duncan, 1999; Grunwald and Flier, 2005; Judelson and Blanco, 2005; Mizubuti and Fry, 1998; Raman et al., 2000). The genus Phytophthora encompasses more than 80 species with $P$. infestans representing perhaps one of the more highly evolved

Received for publication 15 Feb. 2010. Accepted for publication 19 Apr. 2010.

We acknowledge Glades Crop Care for sample contributions. Additionally, we thank Rod Sytsma, Rosa Muchovej, and Buddy Walker for technical support. We also thank the reviewers of this manuscript whose time and effort improved this work overall.

${ }^{1}$ To whom reprint requests should be addressed; e-mailpdr@ufl.edu.
Late blight of potato and tomato caused

electrical conductivity (EC) 5.3.1.9] and peptidase (PEP EC, 3.4.3.1) and DNA fingerprinting through Southern hybridization with the RG57 probe (Goodwin et al., 1992a, 1992b, 1994b; Grunwald et al., 2001). A second marker uses the maternally inherited mitochondrial genome (mtDNA) and has been applied to scenarios varying from population studies to typing herbarium samples from the Irish potato famine (Carter et al., 1990; Gomez-Alpizar et al., 2007; Griffith and Shaw, 1998; Ristaino et al., 2001). These molecular tools when used in combination with the phenotypes for virulence, mating type, and resistance or sensitivity to the phenylamide fungicide metalaxyl have provided a standardized framework for classifying $P$. infestans genotypes (Forbes et al., 1998; Goodwin et al., 1994a).

Before the $1970 \mathrm{~s}$, populations of $P$. infestans in the United States and many countries of the world were predominated by the A1 mating type and some derivative of the US-1 genotype (Andrivon, 1996; Goodwin et al., 1994a). In Florida, late blight epidemics were infrequent until the early 1990s when conducive conditions likely allowed for the migration of new genotypes from Mexico (Goodwin and Drenth, 1997; Goodwin et al., 1995b). The first novel genotype observed in Florida was US-6 (A1 mating type) in 1991 (Goodwin et al., 1994a; Weingartner and Tombolato, 2004). Both US-6 and US-7 (A2 mating type) had been reported within a single field as early as 1993 (Goodwin et al., $1995 b$ ). In Florida, by 1994, the US- 8 genotype had appeared and by 1996, the US-17 genotype and possible progeny of US- $6 \times$ US-8 was recovered from tomato (Goodwin et al., 1998). We suspect that novel genotypes may be responsible for severe late blight epidemics that have been occurring since 2005. The goal of the current study was to characterize the genotypes of $P$. infestans recovered from tomato and potato grown in production regions in southern and central Florida over multiple seasons.

\section{Materials and Methods}

species (Blair et al., 2007; Göker et al., 2007; Kroon et al., 2004). This is evidenced by its host specialization, formation of haustoria, near-obligate tendencies, and aerial et al., 1993; Fry and Mizubuti, 1998). Phytophthora infestans is a heterothallic species requiring the presence of both the $\mathrm{A} 1$ and $\mathrm{A} 2$ mating types for production of sexually recombinant oospores and sexual recombination (Erwin and Ribeiro, 1996; Galindo and Gallegly, 1960; Smoot et al., 1958). Tomato and potato production is chronically plagued by late blight epidemics resulting from conditions during the growing season in south Florida. Late blight impacts Florida's winter tomato crop, a $\$ 464$ million industry that accounted for $36 \%$ of the national production of fresh tomatoes in 2007 (National Agricultural Statistic Service, USDA).

Early genetic investigations of $P$. infestans populations relied on the use of isozymes, namely glucose-6-phosphate isomerase [GPI, dispersal of asexual spores (Fry, 2008; Fry

Stramenopile cultures. Isolates were obtained from leaf, stem, and fruit of tomato $(85 \%)$ and potato $(15 \%)$ plants in central and south Florida during the fall/spring (August/ May) growing seasons spanning 3 years $(2004-2005=2005 ; 2005-2006=2006$; and $2006-2007=2007$ ). Samples were obtained from southwest Florida, including Hendry, Collier, and Lee counties and from the west-central Florida county of Manatee and the east coast, Palm County. Infected leaf tissue was placed in a petri plate on a moistened sterile filter paper, wrapped with parafilm, and incubated at $20{ }^{\circ} \mathrm{C}$ in darkness. Fruit and stem samples were treated similarly, with the exception that plastic clam food boxes $(14 \times 14 \times 7 \mathrm{~cm}$; Dart Contrainer Corp., Mason, MI) were used in place of petri plates. Tissue was monitored daily for sporulation, and sporangia were picked with the tip of a sterile scalpel and transferred onto 
agar plates of either Rye seed A agar (RSA) or barley potato dextrose agar (BPDA) amended with $150 \mu \mathrm{g} \cdot \mathrm{mL}^{-1}$ ampicillin (Caten and Jinks, 1967; Erwin and Ribeiro, 1996). Single-spore isolation was performed by picking sporangia from a sporulating lesion and placing in a $1.5-\mathrm{mL}$ microcentrifuge tube containing $1 \mathrm{~mL}$ of $0.8 \%$ water agar amended with $300 \mu \mathrm{g} \cdot \mathrm{mL}^{-1}$ ampicillin warmed to $35^{\circ} \mathrm{C}$. The suspension was vortexed for $30 \mathrm{~s}$ and poured on BPDA amended with ampicillin. Plates were incubated at $20{ }^{\circ} \mathrm{C}$ for $24 \mathrm{~h}$ and when a single, germinating, sporangium was detected through a stereomicroscope, lifted with a bit of agar using the tip of a sterile scalpel, and placed either into pea broth (Wangsomboondee et al., 2002) or on BPDA.

We evaluated BPDA, RSA, and V8-juice agar (V8A) media to determine if there was a nutritional preference for two isolates representing US-20 (Pi052 and Pi058) and two representing US-21 (Pi0626 and Pi06339). The same media, also tested in the same experiments, were amended with $5 \%$ activated charcoal (AC) to test for growth enhancement because $\mathrm{AC}$ is reported to improve the growth of $P$. infestans without interfering with sporulation (Caten and Jinks, 1967; Erwin and Ribeiro, 1996). Three plates per treatment per isolate were inoculated with a $5.0-\mathrm{mm}$ plug of mycelia taken from an actively growing colony of $P$. infestans and incubated at $20{ }^{\circ} \mathrm{C}$ in the dark. After $7 \mathrm{~d}$, the colony diameter was measured in two orthogonal directions; these experiments were repeated four times. The data were analyzed using SAS (Version 9.1; Cary NC) using PROC GLM and the means were separated by Fisher's protected least significant difference.

Phenotypic characterization. Mating types were determined as has been described previously (Grunwald et al., 2001). Plugs of isolates representing 42 cultures were paired on RSA agar and V8A plates either with US940501 (A1) or Pi02-007 (A2) tester isolates. The plates were then sealed with parafilm, incubated at $15{ }^{\circ} \mathrm{C}$ in darkness for 3 to 4 weeks, and then examined microscopically for the presence of oospores.

Phenylamide sensitivity was assessed by placing a 7-mm agar plug from 1-week-old cultures on three $100 \times 15-\mathrm{mm}$ plates of RSA agar and three $100 \times 15-\mathrm{mm}$ plates of RSA amended with $100 \mu \mathrm{g} \cdot \mathrm{mL}^{-1}$ metalaxyl (Ridomil@ 2E) (Deahl et al., 1995). Plates were incubated at 18 to $21{ }^{\circ} \mathrm{C}$ for $7 \mathrm{~d}$, and colony diameters were measured once average growth diameters reached $15 \mathrm{~mm}$ on unamended plates and again $3 \mathrm{~d}$ later. Each isolate was tested at least twice. The percentage reduction in growth compared with growth on the unamended control plates was calculated. Isolates were designated as metalaxyl-resistant if growth was greater than $60 \%$ of the control, intermediate if growth was $10 \%$ to $60 \%$ of the control, or sensitive if growth was less than $10 \%$ of the control using previously described criteria (Shattock, 1988).

In-planta assays. Tomato plants of cultivar FL-47 were used for all pathogenicity experiments. Plants were maintained in growth chambers at $25{ }^{\circ} \mathrm{C}$ receiving $14 \mathrm{~h}$ light before inoculation. Two US-20 tomato isolates (Pi052, Pi058) and two US-21 (Pi06268 and Pi06339) were used in pathogenicity assays. Inoculum was prepared by growing cultures on RSA for 2 weeks at $18{ }^{\circ} \mathrm{C}$ in darkness, then flooding plates with $10 \mathrm{~mL}$ of $4{ }^{\circ} \mathrm{C} \mathrm{H}_{2} \mathrm{O}$, and rubbing to dislodge sporangia. The suspension was then filtered through four layers of cheesecloth. Sporangia were counted with a hemacytometer, and distilled water was used to adjust the suspension to $1 \times 10^{4}$ sporangia $/ \mathrm{mL}$. In detached leaf assays, two leaflets were placed abaxial side up in a $100 \times 15-\mathrm{mm}$ plate with moistened filter paper. A $10-\mu \mathrm{L}$ aliquot of the sporangial suspension was spotted onto each leaf. Inoculated leaflets were maintained in an incubator at $18^{\circ} \mathrm{C}$ and a $14 / 10$-h light/dark cycle. Lesion size was estimated as the percentage of the leaf area exhibiting symptoms. Detached leaf assays were repeated three times.

For intact plant assays, tomatoes were grown in $10-\mathrm{cm}$ pots containing Metro-Mix 3000 with 6 g Scotts Miracle Gro Osmocote $14 \mathrm{~N}-4.2 \mathrm{P}-11.6 \mathrm{~K}$ in the greenhouse. At 4 weeks of age, plants were moved $3 \mathrm{~d}$ before inoculation to a growth chamber set at $20 / 15{ }^{\circ} \mathrm{C}$ with a $14 / 10$-h light/dark cycle. Five plants per isolate were sprayed until runoff using a handheld aerosol mister with the sporangial suspension prepared as described previously. Untreated plants were sprayed with distilled water. After inoculation, plants were placed in clear plastic bags that had been sprayed with distilled water and returned to the growth chamber. Symptoms were evaluated $5 \mathrm{~d}$ after inoculation, estimating the disease severity as the percentage of total tissue that was symptomatic. Intact plant assays were repeated three times. The mean difference in disease severity was analyzed using an unpaired Student's $t$ test.

Genotypic characterization. Genotypes at two polymorphic allozyme loci, Gpi-1 (GPI EC 5.3.1.9.) and Pep-1 (PEP, EC 3.4.3.1.), were determined using protocols of described in Goodwin et al. (1995a). Similarly, genomic fingerprinting was conducted using the RG57 probe as described previously (Chen et al., 2009; Goodwin et al., 1992a). For ease of visualization, RG57 profile data were transformed to binary data and complied with those data of previously published US genotypes (Goodwin and Drenth, 1997; Goodwin et al., 1998; Wangsomboondee et al., 2002). Mitochondrial DNA haplotypes were determined by polymerase chain reaction-restriction fragment length polymorphism (PCRRFLP) according to Griffith and Shaw (1998). The P2 amplicon was generated with primers F2/R2 and the F4 amplicon was amplified with $\mathrm{F} 4 / \mathrm{R} 4$; products were confirmed by agarose electrophoresis. The resulting P2 amplicon was digested with $M s p \mathrm{I}$ and the F4 amplicon was digested with EcoRI. Restriction profiles were resolved on a $\%$ agarose gel (Griffith and Shaw, 1998). Characterization of genotypes followed the
Phytophthora infestans global marker database (Forbes et al., 1998).

\section{Results}

Isolation and culture. Seventy-six isolates were recovered from tomato and potato during Fall 2004 through Spring 2007 representing three winter growing seasons. Significant differences were detected between the growth of the two genotypes $(P<0.0001)$ on all media. Isolates from 2005 grown on BPDA-AC and V8-AC had significantly greater colony diameters compared with 2006 isolates on these same media. At $20^{\circ} \mathrm{C}$, isolates from 2005 grew on all media but growth diameter was slightly increased with $5 \%$ AC amendment but not significantly (Fig. 1). The diameter of the colonies for isolates from 2006 was greatest on RSA, RSA-AC, and V8-AC, whereas growth was significantly reduced $(P<0.0001)$ on other media.

Detached leaf and intact plant assays. Both US-20 and US-21 isolates produced typical, large, blighted lesions with abundant sporulation. However, inoculation with US20 isolates consistently resulted in a significantly higher percentage disease severity $(P<0.0001)$ when compared with the US-21 isolate (Fig. 2).

Metalaxyl sensitivity. Eighty percent of isolates $(\mathrm{n}=15)$ from 2005 , proposed as US-20, were sensitive to metalaxyl and $20 \%$ exhibited intermediate resistance (Table 1). Proposed US-21 isolates $(n=16)$ from 2006 were $38 \%$ sensitive, $31 \%$ intermediate, and $31 \%$ resistant and US-21 isolates $(n=14)$ recovered in 2007 were 50:50 sensitive and intermediate.

Mating type. All of the isolates $(\mathrm{n}=45)$ were the A2 mating type regardless of host, geographical location, or year of isolation. The sole exception was the US- 8 potato isolate (Pi0626) recovered in 2006, which appeared self-fertile (Table 1).

Genotypic characterization. Isolates recovered in 2005, designated as US-20, were homozygous (100/100) at the Gpi locus and have the RG57 profile presented in Table 1. We propose US-21 for tomato isolates from $2006(n=23)$ and $2007(n=35)$, which were heterozygous 100/122 at the Gpi locus and are polymorphic from the US-20 in the RG57 profile (Table 2). One isolate recovered in 2006 from potato was observed to be 100 / $111 / 122$ at the Gpi locus and had a RG57 profile identical to that of US-8. All isolates recovered were homozygous $(100 / 100)$ at the Pep locus. Similarly, PCR-RFLP of mtDNA indicated that all of the isolates from 2005 to $2007(\mathrm{n}=30)$ were the Ia haplotype. Consistent with the shift from the 100/100 Gpi profile to $100 / 122$, isolates representing US21 exhibited a unique RG57 profile different from US-20 isolates.

\section{Discussion}

Our analysis of $P$. infestans isolates recovered from tomato and potato in Florida 


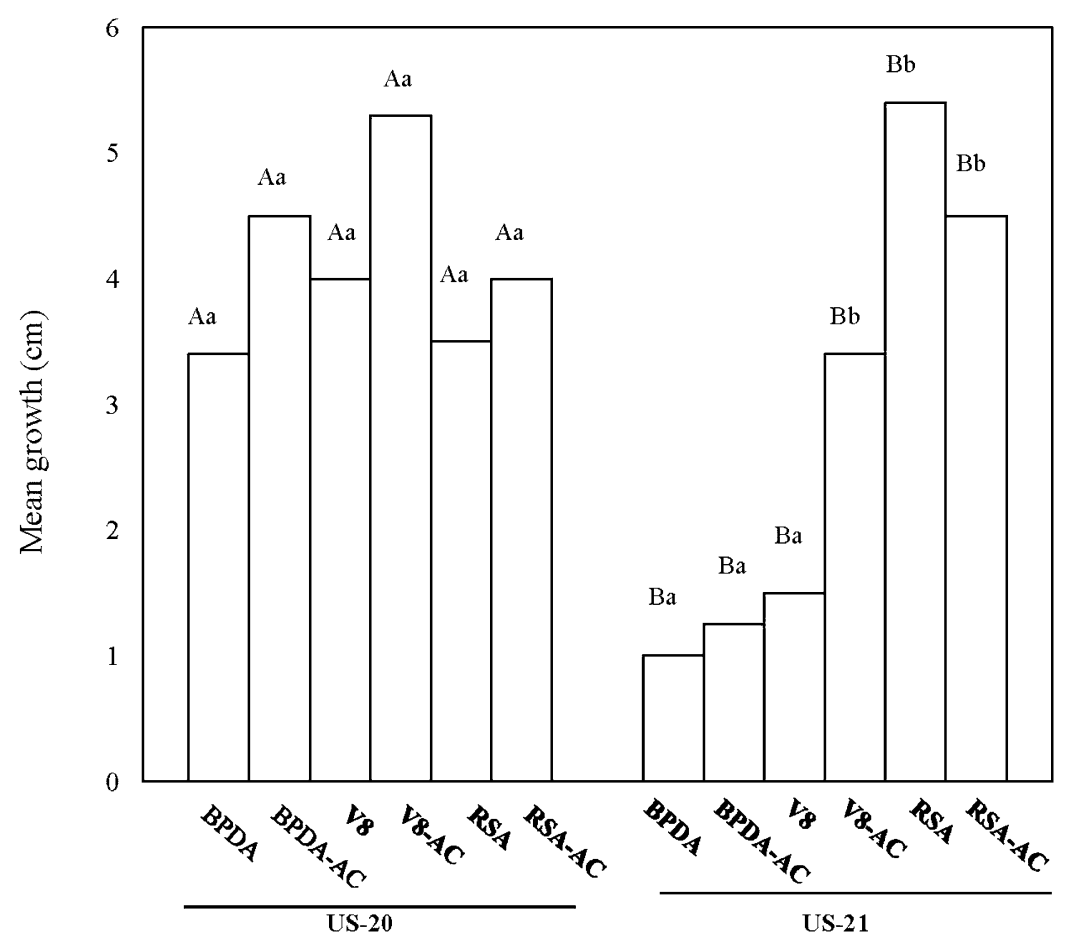

Fig. 1. Mean diameter growth of three US-20 and three US-21 genotypes of $P$. infestans colonies on different media (BPDA= barley-potato dextrose agar; V8 $=$ V8 juice agar; $\mathrm{RSA}=$ rye seed agar; $\mathrm{AC}=$ $5 \%$ activated carbon). Statistical differences detected by genotype (A, B) and media within genotype (a, b) at $P<0.0001$.

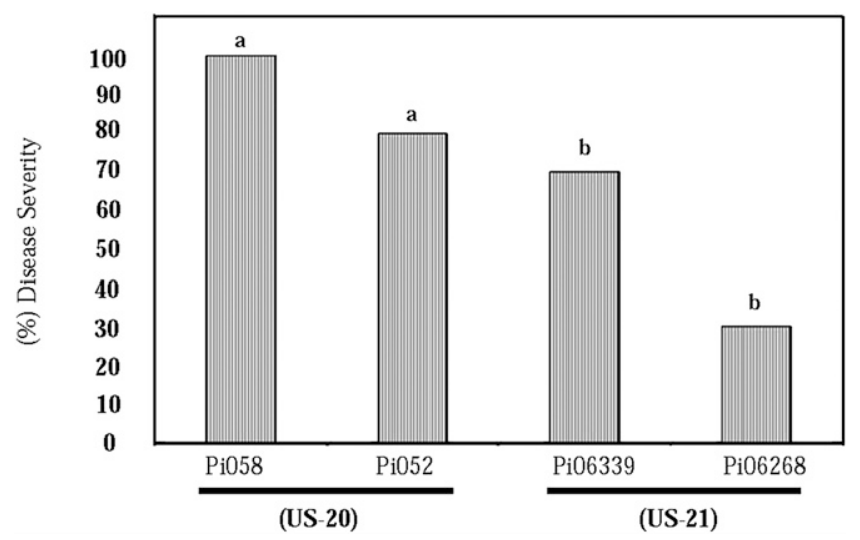

Fig. 2. Disease severity (\% of infected tissue) of two US-20 (Pi058 and Pi052) isolates and two US-21 isolates (Pi0662 and Pi0628) inoculated on FL 47 tomato (mean of two experiments). Columns with different letters $(\mathrm{a}, \mathrm{b})$ are statistically different at $P<0.0001$.

Table 1. Metalaxyl sensitivity of Phytophthora infestans isolates collected in Florida from 2005 to 2007.

\begin{tabular}{lcccc}
\hline & \multicolumn{4}{c}{ Number of isolates } \\
\cline { 2 - 5 } Yr & Total & Sensitive & Intermediate & Resistant \\
\hline 2005 & 15 & 12 & 3 & 0 \\
2006 & 16 & 6 & 5 & 5 \\
2007 & 14 & 7 & 7 & 0 \\
\hline
\end{tabular}

through growing seasons 2005 to 2007 identified unique genotypes not previously described within the United States. In 2005, isolates were similar to the US-13 genotype based on mating type, mtDNA, and isozyme potato in Florida for over 12 years (Goodwin et al., 1998). It would appear that the US-8 clonal lineage is endemic in Florida's potato production.

Isolates of $P$. infestans have been observed to be resistant to the phenylamide metalaxyl since the 1990s. Phenylamide resistance is related to a single dominant gene and levels of sensitivity may involve minor genes (Fabritius et al., 1997; Lee et al., 1999). Isolates of the same genotype in Florida varied in sensitivity to phenylamide, similar to reports elsewhere (Fraser et al., 1999; Goodwin et al., 1998). Metalaxyl-resistant isolates have higher fitness compared with sensitive isolates, and this might contribute to the increased difficulty in managing the novel isolates (Goodwin et al., 1996; Kadish and Cohen, 1988, 1992).

Mitochrondrial haplotypes Ia and IIa are associated with the migration of $P$. infestans populations into Europe around 1976, whereas haplotype IIb was limited to North America (Day and Shattock, 1997; Griffith and Shaw, 1998). All our isolates are of the mtDNA Ia haplotype, which agrees with the findings of others that the "old" genotype isolates representing those present before the identification of A2 mating types outside Mexico have been or are being displaced by "new" genotypes (Day and Shattock, 1997; Fry et al., 1993; Goodwin et al., 1995c; Spielman et al., 1991).

Late blight has been documented infecting potatoes in Florida as early as 1937 (Eddins, 1945). Likewise, P. infestans has been a persistent problem for tomato and potato growers Florida since 1993. This work was initiated as a result of an outbreak of late blight that occurred in the 2004-2005 (2005) growing season. This outbreak was unusual because the disease was particularly destructive to tomato, extremely difficult to control despite intensive spray programs, and it persisted through the end of the season. South Florida growers typically encounter late blight only during the coldest months of the season (December to March) and can generally achieve good control with fungicides. The growth chamber inoculations demonstrated that the US-20 isolates from 2005 caused statistically significant more disease severity on tomato under the same conditions when compared with US-21 isolates from 2006 (Fig. 2). All of the isolates produced symptoms on tomato, although the potato isolate Pi0639 caused the least disease severity in this test.

The observation of the potato isolate resembling US- 8 and its production of oospores in single culture prompts inquiry as to whether these sexual structures are occurring in natural settings and playing a role in the next year's epidemics. Oospores in a single culture of $P$. infestans have been reported in the literature throughout the years (Gallegly and Galindo, 1958; Groves, 2002; Smart et al., 1998; Vartanian and Endo, 1985). Oospore formation is driven by pheromones produced and perceived by the opposite mating type; however, factors such as 
Table 2. Summary of $P$. infestans genotypes of based on mating type, metalaxyl sensitivity, Gpi, and Pep, mtDNA haplotype, and RG57 fingerprint from tomato and potato in South Florida from 2005 to 2007.

\begin{tabular}{llllllllrr}
\hline Genotype & Isolate ID & Yr & Host & MT & MS & Gpi & Pep & mtDNA & RG57 \\
\hline US-20 & Pi052 & 2005 & Tomato & A2 & I & $100 / 100$ & $100 / 100$ & Ia & 1010101001001101010110011 \\
US-20 & Pi058 & 2005 & Tomato & A2 & S & $100 / 100$ & $100 / 100$ & Ia & 1010101001001101010110011 \\
US-8 & Pi0626 & 2006 & Potato & A2 & R & $100 / 111 / 122$ & $100 / 100$ & Ia & 1001100001001101000110111 \\
US-21 & Pi0639 & 2006 & Tomato & A2 & S & $100 / 122$ & $100 / 100$ & Ia & 1000100001001100010110011 \\
US-21 & Pi07009 & 2007 & Tomato & A2 & S & $100 / 122$ & $100 / 100$ & Ia & 1000100001001100000110111 \\
US-21 & Pi07026 & 2007 & Tomato & A2 & I & $100 / 122$ & $100 / 100$ & Ia & 1000100001001100000110111 \\
\hline
\end{tabular}

${ }^{z}$ Self-fertile in a single culture.

$\mathrm{MT}=$ mating type; $\mathrm{MS}=$ metalxyl sensitivity $\mathrm{S}=$ Sensitive; $\mathrm{I}=$ Intermediate; $\mathrm{R}=$ Resistant.

genotype, growth medium, presence of fungicides, and age of the culture influence the health and abundance of oospores observed (Smart et al., 1998). The presence of a selffertile isolate or of both mating types does not guarantee the production of viable oospores because abortion, sexual incompatibility, and lethal factors have been reported in $P$. infestans (Erwin and Ribeiro, 1996; Flier et al., 2001). Additionally, oospore production and fecundity depend on the particular combination of parental genotypes (Flier et al., 2001). The detection of a single isolate that may be self-fertile may have implications for field survival in the field in south Florida.

Factors important to late blight epidemics such as the origin of inoculum, rate and pattern of spread, and mechanisms of survival between seasons by "oversummering" are still unknown in Florida. Although our observations are based on a survey, intensive sampling throughout the season would likely provide insight on the source(s) of inoculum and survival mechanisms in Florida and perhaps other production regions in the United States. Future studies may allow for the elucidation of migration pathways responsible for the introduction of novel $P$. infestans genotypes into Florida and possibly the United States.

\section{Literature Cited}

Andrivon, D. 1996. The origin of Phytophthora infestans populations present in Europe in the 1840s: A critical review of historical and scientific evidence. Plant Pathol. 45:10271035.

Birch, P.R. and S.C. Whisson. 2001. Phytophthora infestans enters the genomics era. Mol. Plant Pathol. 2:257-263.

Blair, J.E., M.D. Coffey, S.Y. Park, D.M. Geiser, and S. Kang. 2007. A multi-locus phylogeny for Phytophthora utilizing markers derived from complete genome sequences. Fungal Genet. Biol. 45:266-277.

Carter, D.A., S.A. Archer, K.W. Buck, D.S. Shaw, and R.C. Shattock. 1990. Restriction fragment length polymorphisms of mitochondrial DNA of Phytophthora infestans. Mycol. Res. 94: 1123-1128.

Caten, C.E. and J.L. Jinks. 1967. Spontaneous variability of single isolates of Phytophthora infestans: I. Cultural variation. Can. J. Bot. 46:329-348.

Chen, C.H., T.C. Wang, L. Black, Z.M. Sheu, F.G. Perez, and K.L. Deahl. 2009. Phenotypic and genotypic changes in the Phytophthora infestans population in Taiwan-1991 to 2006. J. Phytopathol. 157:248-255.
Day, J.P. and R.C. Shattock. 1997. Aggressiveness and other factors relating to displacement of populations of Phytophthora infestans in England and Wales. Eur. J. Plant Pathol. 103: 379-391.

Deahl, K.L., S.P. DeMuth, S.L. Sinden, and A. Rivera-Peña. 1995. Identification of mating types and metalaxyl reisitance in North American populations of Phytophthora infestans. Amer. J. Potato Res. 72:35-49.

Duncan, J. 1999. Phytophthora - an abiding threat to our crops. Microbiol. Today 26:114-116.

Eddins, A.H. 1945. Transmission and spread of late blight in seed potatoes. Amer. J. Potato Res. 22:333-339.

Erwin, D.C. and O.K. Ribeiro. 1996. Phytophthora diseases worldwide. APS Press, St. Paul, MN.

Fabritius, A.-L., R.C. Shattock, and H.S. Judelson. 1997. Genetic analysis of metalaxyl insensitivity loci in Phytophthora infestans using linked DNA markers. Phytopathology 87:1034-1040.

Flier, W.G., N.J. Grunwald, W.E. Fry, and L.J. Turkensteen. 2001. Formation, production and viability of oospores of Phytophthora infestans from potato and Solanum demissum in the Toluca Valley, central Mexico. Mycol. Res. 105: 998-1006.

Forbes, G.A., S.B. Goodwin, A. Drenth, P. Oyarzun, M.E. Ordoñez, and W.E. Fry. 1998. A global marker database for Phytophthora infestans. Plant Dis. 82:811-818.

Fraser, D.E., P.B. Shoemaker, and J.B. Ristaino. 1999. Characterization of isolates of Phytophthora infestans from tomato and potato in North Carolina from 1993 to 1995. Plant Dis. 83:633-638

Fry, W.E. 2008. Phytophthora infestans: The plant (and $R$ gene) destroyer. Mol. Plant Pathol. 9:385-402.

Fry, W.E., S.B. Goodwin, A.T. Dyer, J.M. Matuszak, A. Drenth, P.W. Tooley, L.J. Sujkowski, Y.J. Koh, B.A. Cohen, L.J. Spielman, K.L. Deahl, D.A. Inglis, and K.P. Sandlen. 1993. Historical and recent migrations of Phytophthora infestans: Chronology, pathways, and implications. Plant Dis. 77:653-661.

Fry, W.E. and E.S.G. Mizubuti. 1998. Potato late blight. In: Jones, D.G. (ed.). The epidemiology of plant diseases. Springer, Dordrecht, The Netherlands.

Galindo, J.A. and M.E. Gallegly. 1960. The nature of sexuality in Phytophthora infestans. Phytopathology 50:123-128.

Gallegly, M.E. and J.A. Galindo. 1958. Mating types and oospores of Phytophthora infestans in nature in Mexico. Phytopathology 48:274-277.

Göker, M., H. Voglmayr, A. Riethmüller, and F. Oberwinkler. 2007. How do obligate parasites evolve? A multi-gene phylogenetic analysis of downy mildews. Fungal Genet. Biol. 44:105-122.

Gomez-Alpizar, L., I. Carbone, and J.B. Ristaino. 2007. An Andean origin of Phytophthora infestans inferred from mitochondrial and nu- clear gene genealogies. Proc. Natl. Acad. Sci. USA 104:3306-3311.

Goodwin, S.B., B.A. Cohen, K.L. Deahl, and W.E. Fry. 1994a. Migration from northern Mexico as the probable cause of recent genetic changes in populations of Phytophthora infestans in the United States and Canada. Phytopathology 84:553-558.

Goodwin, S.B., B.A. Cohen, and W.E. Fry. 1994b. Panglobal distribution of a single clonal lineage of the Irish potato famine fungus. Proc. Natl. Acad. Sci. USA 91:11591-11595.

Goodwin, S.B. and A. Drenth. 1997. Origin of the A2 mating type of Phytophthora infestans outside Mexico. Phytopathology 87:992-999.

Goodwin, S.B., A. Drenth, and W.E. Fry. 1992a. Cloning and genetic analyses of two highly polymorphic moderately repetitive nuclear DNAs from Phytophthora infestans. Curr. Genet. 22:107-115.

Goodwin, S.B., L.J. Spielman, J.M. Matuszak, S.N. Bergeron, and W.E. Fry. 1992b. Clonal diversity and genetic differentiation of Phytophthora infestans populations in northern and central Mexico. Phytopathology 82:955-961.

Goodwin, S.B., R.E. Schneider, and W.E. Fry. 1995a. Use of cellulose-acetate electrophoresis for rapid identification of allozyme genotypes of Phytophthora infestans. Plant Dis. 79:11811185.

Goodwin, S.B., C.D. Smart, R.W. Sandrock, K.L. Deahl, Z.K. Punja, and W.E. Fry. 1998. Genetic change within populations of Phytophthora infestans in the United States and Canada during 1994 to 1996: Role of migration and recombination. Phytopathology 88:939-949.

Goodwin, S.B., L.J. Sujkowski, and W.E. Fry. 1996. Widespread distribution and probable origin of resistance to metalaxyl in clonal genotypes of Phytophthora infestans in the United States and Canada. Phytopathology 86:793-800.

Goodwin, S.B., L.J. Sujkowski, A.T. Dyer, B.A. Fry, and W.E. Fry. 1995b. Direct detection of gene flow and probable sexual reproduction of Phytophthora infestans in northern North America. Phytopathology 85:473-479.

Goodwin, S.B., L.S. Sujkowski, and W.E. Fry. 1995c. Rapid evolution of pathogenicity within clonal lineages of the potato late blight disease fungus. Phytopathology 85:669-676.

Griffith, G.W. and D.S. Shaw. 1998. Polymorphisms in Phytophthora infestans: Four mitochondrial haplotypes are detected after PCR amplification of DNA from pure cultures or from host lesions. Appl. Environ. Microbiol. 64:4007-4014.

Groves, C.L. 2002. Characterization of Phytophthora infestans from Maine during 1999 and 2000. Amer. J. Potato Res. 79:325-333.

Grunwald, N.J. and W.G. Flier. 2005. The biology of Phytophthora infestans at its center of origin. Annu. Rev. Phytopathol. 43:171-190.

Grunwald, N.J., W.G. Flier, A.K. Sturbaum, E. Garay Serrano, T.B.M. van den Bosch, C.D. 
Smart, J.M. Matuszak, H. Lozoya Saldaña, L.J. Trurkensteen, and W.E. Fry. 2001. Population structure of Phytophthora infestans in the Toluca valley region of central Mexico. Phytopathology 91:882-890.

Judelson, H.S. and F.A. Blanco. 2005. The spores of Phytophthora: Weapons of the plant destroyer. Nat. Rev. Microbiol. 3:47-58.

Kadish, D. and Y. Cohen. 1988. Competition between metalaxyl-sensitive and metalaxylresistant isolates of Phytophthora infestans in the absence of metalaxyl. Plant Pathol. 37: 558-564.

Kadish, D. and Y. Cohen. 1992. Overseasoning of metalaxyl-sensitive and metalaxyl-resistant isolates of Phytophthora infestans in potato tubers. Phytopathology 82:887-889.

Kroon, L.P.N.M., F.T. Bakker, G.B.M. van den Bosch, P.J.M. Bonants, and W.G. Flier. 2004. Phylogenetic analysis of Phytophthora species based on mitochondrial and nuclear DNA sequences. Fungal Genet. Biol. 41: 766-782.
Lee, T.Y., E.S.G. Mizubuti, and W.E. Fry. 1999. Genetics of metalaxyl resistance in Phytophthora infestans. Fungal Genet. Biol. 26:118-130.

Mizubuti, E.S.G. and W.E. Fry. 1998. Temperature effects on developmental stages of isolates from three clonal lineages of Phytophthora infestans. Phytopathology 88:837-843.

Raman, K.V., N.J. Grunwald, and W.E. Fry. 2000. Promoting international collaboration for potato late blight disease management. Pestic. Outlook 11:181-185.

Ristaino, J.B., C.T. Groves, and G.R. Parra. 2001 PCR amplification of the Irish potato famine pathogen from historic specimens. Nature 411: 695-697.

Shattock, R.C. 1988. Studies on the inheritance of resistance to metalaxyl in Phytophthora infestans. Plant Pathol. 37:4-11.

Smart, C.D., M.R. Willmann, H. Mayton, E.S.G. Mizubuti, R.W. Sandrock, A.E. Muldoon, and W.E. Fry. 1998. Self-fertility in two clonal lineages of Phytophthora infestans. Fungal Genet. Biol. 25:134-142.
Smoot, J.J., F.J. Gough, H.A. Lamey, J.J. Eichnemuller, and M.E. Gallegly. 1958. Production and germination of oospores of Phytophthora infestans. Phytopathology 48:165-171.

Spielman, L.J., A. Drenth, L.C. Davidse, L.J. Sujkowski, W. Gu, P.W. Tooley, and W.E. Fry. 1991. A second world-wide migration and population displacement of Phytophthora infestans? Plant Pathol. 40:422-430.

Vartanian, V.G. and R.M. Endo. 1985. Overwintering hosts, compatibility types, and races of Phytophthora infestans on tomato in southern California. Plant Dis. 69:516-519.

Wangsomboondee, T., C. Trout Groves, P.B. Shoemaker, M.A. Cubeta, and J.B. Ristaino. 2002. Phytophthora infestans populations from tomato and potato in North Carolina differ in genetic diversity and structure. Phytopathology 92:1189-1195.

Weingartner, D.P. and D. Tombolato. 2004. Temporal, geographic and host distribution of Phytophthora infestans genotypes in Florida. Amer. J. Potato Res. 81:95. 